\title{
How CATIE brought us back to Kansas: a critical re-evaluation of the concept of atypical antipsychotics and their place in the treatment of schizophrenia
}

\author{
David Cunningham Owens
}

\begin{abstract}
The subdivision of the class of antipsychotic drugs into two discrete groups - 'conventional' (or first generation) and 'atypical' (or second generation) - has been adopted as standard, with the latter generally accepted as 'better' and widely recommended as automatic first-line choices. However, this perception has been thrown into confusion with the results of large pragmatic trials that failed to identify advantages with the new, more expensive drugs, while identifying worrying tolerability issues. This article explores the origins of 'atypicality', its construction on the back of a confusing and weak clinical validator (diminished liability to promote parkinsonism) and how even in relation to the archetypical atypical, clozapine, the uncertain boundaries of drug-induced extrapyramidal dysfunction may be contributing to confusion about 'efficacy' and 'tolerability'. It argues that abandoning atypicality would open up clinical practice to all drugs of a single class of 'antipsychotics' and allow for individualised risk/benefit appraisal as a basis for truly tailored treatment recommendations.
\end{abstract}

Sometimes, the best way forward is back - to take stock, appraise anew, admit mistakes. This is never easy, especially if shadows haunt the way but, if necessary, is better undertaken sooner than later and with honesty. It might be argued that there is a strong suggestion that psychiatry has been engaging in sufficient wish-fulfilment to make such a backward step not only useful but essential for quality patient care - and professional validation.

It is over a decade since new antipsychotic drugs were launched to almost universal fanfare. And it did seem there was much to celebrate. On the back of clozapine, the offer was tantalising - not just 'more' but 'better'. It was easy for those reluctant to join the carnival to be so drowned out by the clamour as to feel sceptical of their own scepticism. But now doubt, if not scepticism, has been sown with the results of studies that challenge the perception of new antipsychotics as universally 'better' options for people with schizophrenia. So now may be the time to go back and look with honesty at how this situation evolved and where we are left in relation to future prescribing practice.
This article raises fundamental questions about our understanding of the clinical pharmacology of antipsychotic drugs - so fundamental that (as numerous publication rejections attest) they were until recently considered unpublishable, a victim of the censorship of orthodoxy. Using recent evidence, the ideas are presented here in line with the view that challenging orthodoxy is an essential aspect of scientific debate.

\section{Atypicality: its rise and fall and rise again}

The idea that some antipsychotics might be 'novel' in what they do and 'atypical' in how they do it antedates the present generation to bear the 'atypical' label (Box 1). Generically, it emerged in the 1970s (Costall \& Naylor, 1975; Jenner \& Marsden, 1979) for compounds that might have broader therapeutic profiles, including against negative (i.e. autistic) features (Elizur \&Davidson, 1975), while possessing diminished liability to promote extrapyramidal

David Cunningham Owens is Professor of Clinical Psychiatry at the University of Edinburgh (University Division of Psychiatry, Kennedy Tower, Royal Edinburgh Hospital, Morningside Terrace, Edinburgh EH10 5HF, UK. Email: david.owens@ed.ac.uk) and an honorary consultant psychiatrist at the Royal Edinburgh Hospital. Previously he was a consultant psychiatrist and member of the external scientific staff of the Medical Research Council at the Clinical Research Centre, Northwick Park Hospital, Harrow. He has published extensively on the biology of schizophrenia and authored a well-received textbook on the extrapyramidal side-effects of antipsychotic drugs (Owens, 1999). He continues to participate in sector-based, general adult psychiatric practice. 
Box 1 The seven ages of atypicality: antipsychotics to which the term 'atypical' has been attached

Elderly atypicals

- Clozapine

- Thioridazine

- Pimozide

- Sulpiride

Middle-aged

- Loxapine

- Molindone

- Methotrimeprazine (levomepromazine)

Youthful

- Risperidone

- Olanzapine

- Sertindole

- Quetiapine

- Ziprasidone

Infant

- Aripiprazole

Elderly posing as youthful

- Zotepine

Middle-aged posing as youthful

- Amisulpride

Deceased

- Remoxipride

side-effects. Thioridazine and pimozide were considered in this category but there was resistance to their 'difference', and following the widespread withdrawal of clozapine in 1975, the terms were mainly reserved for substituted benzamides, especially the already marketed sulpiride.

This advocacy was largely theoretically driven by in vitro data from single-dose studies but was challenged by the demonstration that sulpiride's pharmacology seemed more 'typical' with chronic (i.e. repeat) administration (Jenner et al, 1982). Furthermore, clinical results remained contradictory. In head-to-head comparisons it appeared no worse, but effectively little better, than chlorpromazine (Toru et al, 1972) or haloperidol (Cassano et al, 1975). Sulpiride's unusual pharmacokinetics, involving low lipophilicity with poor absorption/brain penetrance, meant that issues of invivo doseequivalence continued to cloud clinical validation and the issue faded.

Clozapine's rehabilitation was key to establishing optimism in psychopharmacology. The results of the US Multicenter Study (Kane et al, 1988) were striking, if less impressive than the enthusiasm they generated. The major finding of a significantly greater improvement rate $(30 \%)$ compared with chlorpromazine and benzatropine (4\%) was based on a modest criterion $(20 \%$ reduction in total score on the Positive and NegativeSyndromeScale,PANSS). None the less, the target population - with operationally defined 'treatment-resistant schizophrenia' - had pessimistic therapeutic prospects and benefits were welcome whatever their size.

Clozapine's broad in vitro binding spectrum, strikingly different from that of the highly $\mathrm{D}_{2}$ selective sulpiride, offered a further possibility progress beyond the dopamine hypothesis, which had come to be seen as sterile (Crow, 1987). The way was set for new launches, beginning with risperidone in 1993, where 'atypical' was not merely a qualifying adjective within a unified class ('antipsychotics') but was elevated to a classificatory term in itself from which difference (group membership) could be inferred. We now had 'two dichotomous groups' of antipsychotic (Kinon \& Lieberman, 1996).

\section{Challenges to atypicality?}

Clozapine could wear an atypical mantle with ease. On other new shoulders this always sat less comfortably. Some reviews found little advantage for new antipsychotics over earlier drugs (Geddes et $a l, 2000)$; others, no proven advantage in treatmentresistant schizophrenia (Chakos et al, 2001); still others, differential efficacy within the group (Davis et al, 2003). Notwithstanding this lack of consensus, the perception of 'added benefit' translated easily to clinical practice, with new drugs rapidly gaining a dominant first-line position.

A revealing insight into how practice variables might have contributed to the positive perception of atypicality came from Rosenheck et al (2003). In their industry-sponsored study, 309 individuals with schizophrenia or schizoaffective disorder were randomly allocated to flexible dose regimes of olanzapine (5-20 mg/day) or haloperidol (5-20 mg/day) and followed over 12 months. To maintain masked status, the haloperidol group were given benzatropine (1-4 mg/day) prophylactically, theolanzapine group an identical dose of placebo. The authors hypothesised that olanzapine would outperform haloperidol on three primary outcomes-symptoms (fewer), quality of life (better), costs (lower).

None of these was supported. Retention and termination due to adverse effects were not different and although olanzapine-treated participants reported modestly reduced akathisia (non-significant after 6 months) and showed significant improvements on some cognitive tests, neither of these translated into improved quality of life. Significantly more olanzapine-treated participants experienced weight gain, and total treatment costs for this group were $4-5$ times higher. 


\section{Box 2 Summary of the CATIE study}

Pragmatic comparative double-blind randomised trial (18 months) of new antipsychotics (licensed in USA):

- olanzapine (7.5-30 mg/day)

- quetiapine (200-800 mg/day)

- risperidone (1.5-6 mg/day)

- ziprasidone (40-160 mg/day)

- comparator: perphenazine (8-32 mg/day)

Primary outcome: discontinuation of treatment for any cause (proxy for 'effectiveness')

Participants (in five groups):

$\begin{array}{ll}n & 1493 \\ \text { Age } & 40.0-40.5 \text { years } \\ \text { Gender } & 70-76 \% \text { male } \\ \text { Education } & 12.0-12.2 \text { years } \\ \text { Never married } & 57-63 \% \\ \text { PANSS totals at entry } & 74.3-76.4 \\ \text { CGI score at entry } & 3.9-4.0\end{array}$

(PANSS, Positive and Negative Syndrome Scale; CGI, Clinical Global Impression scale)

(Lieberman et al, 2005)

The authors attributed this striking lack of difference to enhanced performance of haloperidol compared with that in the regulatory olanzapine studies and proposed that absence of a prophylactic anticholinergic in the design of these earlier studies seriously compromised haloperidol's performance. The inference is that extrapyramidal side-effects can significantly impede therapeutic potential.

The stoutest blow to atypicality comes from the Clinical Antipsychotic Trials of Intervention Effectiveness (CATIE) study (Box 2). This flexible-dose trial, sponsored by the National Institute of Mental Health, compared the effectiveness over 18 months of all new antipsychotics licensed in the USA at study inception (olanzapine, quetiapine, risperidone; ziprasidone was added after licensing in January 2002; aripiprazole, licensed in November 2002, came too late) against the long-established perphenazine (Lieberman et al, 2005). It was hypothesised that significant differences would be evident between drugs in the primary outcome of discontinuation for any cause, taken as a global, pragmatic proxy for efficacy/safety/tolerability. Overall, $74 \%$ of the sample discontinued before 18 months, the lowest rate $(64 \%)$ being with olanzapine (Table 1$)$. Other outcomes also suggested that olanzapine has some modest advantages over its new rivals and the established antipsychotics (Table 2).
Table 1 CATIE: discontinuation rates over 18 months

$\begin{array}{lcc}\text { Drug } & \begin{array}{c}\text { Mean modal } \\ \text { dose, } \\ \text { mg/day }\end{array} & \begin{array}{c}\text { Patients } \\ \text { discontinuing } \\ \text { drug, \% }\end{array} \\ \text { Olanzapine } & 20.1 & 64 \\ \text { Risperidone } & 3.9 & 74 \\ \text { Perphenazine } & 20.8 & 75 \\ \text { Ziprasidone } & 112.8 & 79 \\ \text { Quetiapine } & 543.4 & 82 \\ \text { Overall discontinuation } & & 74 \\ \text { Source: Lieberman } e t \text { al (2005). } & & \end{array}$

It is, however, adverse effects data that force the considered judgement. Rates of discontinuation owing to intolerable side-effects were greatest with olanzapine $(18 \%)$, least with risperidone $(10 \%)$, significantly more olanzapine-treated participants discontinuing because of weight gain (average $2 \mathrm{lb} /$ month) and metabolic effects (9\%v.1-4\%), which were striking (online data supplement, Table DS1). Although more participants discontinued perphenazine $(8 \% v .2-4 \%)$ because of extrapyramidal sideeffects - parkinsonism, akathisia, tardive dyskinesia - there were no significant differences in their incidence (online data supplement, Table DS2).

\section{Table 2 CATIE: major findings}

\begin{tabular}{|c|c|c|}
\hline Outcome & Drug comparison & $\begin{array}{l}\text { Signi- } \\
\text { ficant } \\
\text { differ- } \\
\text { ence? }\end{array}$ \\
\hline \multicolumn{3}{|l|}{$\begin{array}{l}\text { Time to discon- } \\
\text { tinuation }\end{array}$} \\
\hline \multirow{4}{*}{$\begin{array}{l}\text { Any cause and } \\
\text { patient decision }\end{array}$} & Olanzapine $>$ quetiapine & Yes \\
\hline & Olanzapine $>$ risperidone & Yes \\
\hline & Olanzapine $>$ ziprasidone & No \\
\hline & Olanzapine $>$ perphenazine & No \\
\hline \multirow[t]{4}{*}{ Lack of efficacy } & Olanzapine $>$ quetiapine & Yes \\
\hline & Olanzapine $>$ risperidone & Yes \\
\hline & Olanzapine $>$ perphenazine & Yes \\
\hline & Olanzapine $>$ ziprasidone & No \\
\hline $\begin{array}{l}\text { Intolerable } \\
\text { side-effects }\end{array}$ & All comparisons & No \\
\hline \multirow{4}{*}{$\begin{array}{l}\text { Duration of } \\
\text { successful } \\
\text { treatment }\end{array}$} & Olanzapine $>$ quetiapine & Yes \\
\hline & Olanzapine $>$ risperidone & Yes \\
\hline & Olanzapine $>$ perphenazine & Yes \\
\hline & Risperidone $>$ quetiapine & Yes \\
\hline $\begin{array}{l}\text { Efficacy (PANSS } \\
\text { totals/CGI) }\end{array}$ & $\begin{array}{l}\text { Improvement all groups: } \\
\text { initially greatest with } \\
\text { olanzapine, but not } \\
\text { sustained }\end{array}$ & \\
\hline
\end{tabular}


The limitations of this study have been acknowledged, including its short duration and relatively low completion rates, sample characteristics, exclusion of participants with tardive dyskinesia from the perphenazine arm, choice and doses of study drugs, reliance on intention-to-treat analysis and differences in pre-study treatments (Rosenheck et al, 2007), but despite these it will surely be seen as seminal to psychopharmacology. The authors were circumspect in their comments, emphasising the limited effectiveness that antipsychotics continue to exert but leaving future patterns of use to how clinicians, patients, families and policy makers evaluate the trade-offs between efficacy and sideeffects' (Lieberman et al, 2005). Within this carefully crafted statement can be deciphered a challenge (see 'Back to basics' below).

Advantage might still accrue to new drugs if costeffectiveness benefits were to be identified. Although several such analyses have been favourable to new drugs, methodological problems cast doubt on the validity of their conclusions (Polsky et al, 2006). In the CATIE study, perphenazine treatment was less costly than treatment with new drugs (Rosenheck et al, 2006). And CATIE is now defended by a CUtLASS! The Cost Utility of the Latest Antipsychotic Drugs in Schizophrenia Study (Jones et al, 2006) was a pragmatic multicentre study across England funded by the National Health Service's Health Technology Assessment Programme (Box 3). It sought to answer a simple question: are initial acquisition costs of new antipsychotics offset by improvements in health-related quality of life or other savings in patients in whom a change of medication is deemed appropriate? The specific hypothesis was that new antipsychotics would be associated with a clinically significant improvement in quality of life over 1 year compared with older drugs. Not only was this not supported - patients failed to express any preference - but also any (slight) benefits tended to favour older drugs, costs with these being (non-significantly) lower. An informative observation was UK clinicians' infrequent use of haloperidol.

Jones et al stated unequivocally that they were 'not presenting a null result; the hypothesis that second generation antipsychotics are superior was clearly rejected'. Although 'surprised', they concluded that 'all the data suggest that careful prescribing of FGAs [first-generation antipsychotics], at least in the context of a trial, is not associated with poorer efficacy or a greater adverse effect burden' (Jones et al, 2006).

\section{Two dichotomous groups?}

These data might make some a little flustered so it may be informative to explore the subtle ways by which atypicality achieved a second incarnation.

\section{Box 3 Summary of CUtLASS findings for} treatment band 1

Band 1 participants were:

- eligible if medication change required for clinical reasons

- randomised to either first- or secondgeneration antipsychotic: $n=227$

Results at 12-month follow-up

- No quality-of-life advantages to secondgeneration antipsychotics

- In terms of quality of life and symptom scores, patients on first-generation antipsychotics showed a trend towards greater improvement

- No clear patient preference

- Similar costs

(Jones et al, 2006)

Atypicality was resurrected enthusiastically despite indications that the corpse was cold. Searching out the unique pharmacological action that would justify the idea that there were indeed 'two dichotomous groups' of antipsychotic has consumed vast endeavour, but while many properties of these drugs have been called, no single one has yet received universal acclamation (Reynolds, 2004). However, clinical criteria could still give it life. Clozapine provided several pointers (see pp. 23-25) but for drugs developed as 'first-line', not 'treatment-resistance', agents there was only one - reduced liability to promote extrapyramidal side-effects. In establishing the validity of atypicality, extrapyramidal side-effects means parkinsonism. This was, and remains, the one characteristic that atypical antipsychotics claim to share - within the therapeutic (i.e. antipsychotic) range, a uniquely diminished liability to promote parkinsonism.

\section{Drug-induced parkinsonism - a robust validator?}

Chlorpromazine's propensity topromoteparkinsonism was recognised from the start and regarded as a clinical manifestation of the desirable pharmacological action. Even after parkinsonism had joined the ranks of adverse, as opposed to therapeutic, effects it was many years before it was viewed negatively. However, drug-induced parkinsonism can be subtle, pervasive, disabling and frequently overlooked or misattributed (Weiden et al, 1987). It tends to resolve over time (Marsden et al, 1986; Ungvari et al, 1999) and may be modified by wider (especially antimuscarinic) pharmacological properties of the drugs whose $\mathrm{D}_{2}$ antagonism causes it (Miller \& Hiley, 1974). It is a 
Box 4 Antipsychotic-induced parkinsonism in people with non-organic conditions

Various predisposing factors and practice variables determine whether parkinsonism is present and whether it is recognised and recorded:

- Increasing age

- Individual predisposition (dopamine 'endowment' and rate of dopaminergic loss)

- Female gender (possibly confounded with dose or other practice variables)

- Higher starting doses

- Rapid rate of increment

- Finishing dose

- Duration of exposure (may resolve with time)

- Inherent liability of compound (potency/ receptor binding profile)

- Breadth of concept (any symptom $v$. syndrome only)

- Sensitivity/breadth of examination (including subjective phenomena)

weak and confusing candidate with which to validate a 'new' subclass of drugs, especially utilising shortterm efficacy alone (Box 4).

The problem of relying on an adverse effect to validate a new classification is that trial differences between the compound thought to be different and a standard comparator may reflect either genuine pharmacological differences or practice differences in the way the two agents are used. This has haunted interpretation of relevant data from the start and raises some questions relating to the conduct of trials in antipsychotic psychopharmacology.

\section{Qualitative issues in antipsychotic drug appraisal}

Psychopharmacology has matured in the past 20 years but remains an infant in the family of science. Problems translating in vitro data to in vivo contexts are great enough but difficulties also lie in trial design and execution which, of necessity, must reflect realities - i.e. any study must first and foremost be 'doable'. As a result, studies are based on a series of assumptions and compromises that are infrequently acknowledged. The following issues are pertinent to the present discussion.

\section{Choice of comparator}

Haloperidol was crowned the gold standard comparator antipsychotic to reflect 'common
Table 3 International antipsychotic prescribing trends (to 1992)

$$
\text { Medication before trial entry }
$$

\begin{tabular}{cclr} 
Oral & $\%$ & Depot & $\%$ \\
\hline $\begin{array}{c}\text { Phenothiazines } \\
\text { Chlorpromazine }\end{array}$ & 53 & Phenothiazines & 21.1 \\
$\begin{array}{c}\text { and thioridazine } \\
\text { Butyrophenones }\end{array}$ & 25.8 & Thioxanthenes & 8.9 \\
Haloperidol & 23.6 & & 5.9 \\
& & & \\
\hline
\end{tabular}

Data from multinational (excluding USA) phase III risperidone study, Janssen-Cilag (with permission).

practice', a justification that surprised those wary of its potentially vicious extrapyramidal proclivities. By the late 1980s it was apparently the market leader antipsychotic, although how much stellar sales reflected liberal use in US emergency rooms was never clear. In fact, whatever the position in the USA, butyrophenones were almost certainly not the psychiatric market leader worldwide (Table 3). The choice is the more perverse, however, when receptor binding and clinical characteristics are considered, even superficially - a selective, high-potency compound of known high (perhaps uniquely high) liability to cause extrapyramidal side-effects (Owens, 1999) v. non-selective, in general lower-potency, compounds postulated to have low extrapyramidal side-effects liability. One wonders what odds a betting layman would have obtained on the outcome of such comparisons.

The importance of comparator choice in extrapyramidal side-effects liability was evident in Kane et al's (1988) multicenter clozapine study, in which simply switching from haloperidol to chlorpromazine, even in doses now considered exceptionally high (up to $1800 \mathrm{mg} /$ day), reduced

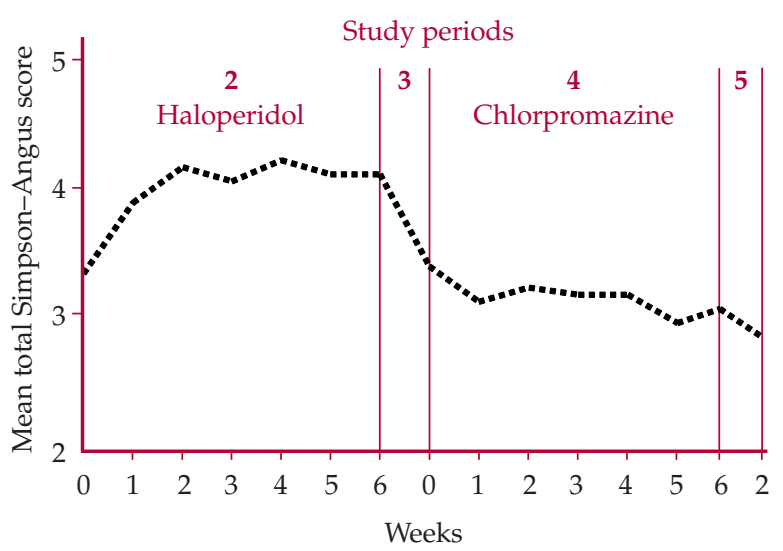

Fig. 1 Extrapyramidal side-effect ratings of patients treated with haloperidol + benzatropine then switched to chlorpromazine + benzatropine (Kane et al, 1988). 
Simpson-Angus ratings (see 'Rating methodology' below) by about $25 \%$ (Fig. 1).

\section{Dose of comparator}

The shift of US psychiatrists to high-dose/highpotency antipsychotic regimes began in the 1980s (Baldessarini et al, 1988). This transatlantic love of high doses even extended to clozapine (Pollack et al, 1995). Baldessarini et al (1984) found that with highpotency drugs, equivalent doses were on average 3.5 times those for patients treated with low-potency drugs. All phase III studies for new antipsychotics used several times the minimum effective dose range for haloperidol, which recent data suggest is as low as $2-5 \mathrm{mg} /$ day (Oosthuizen et al, 2001), a figure identical to theoretical projections from functional imaging (Kapur et al, 1997). In fact, this knowledge is nothing new (McEvoy et al, 1991). Adopting doses of standard comparator drug based on 'common practice' with high-potency drugs in the USA in the late 1980s and early 1990s did not merely set very low the hurdle any new drug had to overcome to establish advantage but had the effect of spiriting the hurdle away altogether.

Although some reviewers concluded that comparator doses played a role in laying down an unlevel playing field (Geddes et al, 2000), this has been strongly refuted (Davis et al, 2003). There are two problems with statistical refutations. First, dose and liability to cause extrapyramidal side-effects may not bear a close linear relationship to one another, particularly with high-potency compounds. Doseresponse relationships with antipsychotics are complex (Baldessarini et al, 1988) and study has resulted in few hard facts. However, it is clinical experience that following dose reductions, such side-effects may resolve suddenly, as if thresholdrelated (Owens, 1998). Second, absolute dosage is important in the expression of extrapyramidal side-effects, but so too is the way ultimate doses are attained. When high-potency antipsychotics are introduced in high dosage to susceptible, drugnaïve individuals, extrapyramidal side-effects emerge rapidly and virtually universally (Chiles, 1978); when initial exposure is low and increments slow, they may not emerge at all, even with highpotency compounds (Rosebush \& Mazurek, 1999; Oosthuizen et al, 2001). As important as where you end dose-wise is where you start (remembering the rise from zero to anything, no matter how small, is probably the greatest increment of all) and how fast you get there (Owens, 1999) (Box 4).

Despite challenge, the issue of inappropriate comparator dosage continues to stalk interpretation of studies claiming extrapyramidal side-effects advantage for new antipsychotics.

\section{Other issues}

Trial duration Duration of drug trials is necessarily limited but when parkinsonism is a focus this can be crucial. Drug-induced parkinsonism tends to resolve over weeks or months, so an advantageous extrapyramidal side-effects profile after $6-8$ weeks of an efficacy study does not mean that such shortterm benefit will be sustained. Comparing clozapine with chlorpromazine, Lieberman et al (2003) found that significant advantage to clozapine in terms of parkinsonism at 6 months lost significance by 12 months.

Rating methodology This is crucial. Unlike neurology, psychiatry remains wedded to a single parkinsonism scale, the Simpson-Angus Extrapyramidal Symptoms Rating Scale (Simpson \& Angus, 1970). Debate remains about its item construction, especially its strong bias towards rigidity, which compared with bradykinesia is a minor feature of drug-induced disorder (Owens, 1999). It further ignores subjective symptomatology. Recent work suggests that the Simpson-Angus is reliable but the traditional cut-off (0.3) is far too low, thus compromising specificity (Janno et al, 2005), a crucial point in interpretation.

LOCF Analysis of data using 'last observation carried forward' (LOCF) is the standard statistical method to which data from all trials of new drugs was subjected but, it is suggested, this may have contributed advantage to new antipsychotics (Rosenheck, 2005). Although this has not received unqualified support (Leucht et al, 2007), there remains an issue about what is the appropriate method by which to analyse data from studies with high drop-out rates that may differentially affect the groups being compared.

Sponsorship The influence of industry sponsorship in outcomes of clinical trials has been much discussed, with clear evidence that this is a potent factor in attributing advantage to trial compounds, including new antipsychotics (Heres et al, 2006).

Efficacy $v$. effectiveness When placing trial-based recommendations in meaningful clinical contexts, the distinction between 'efficacy' (performance under 'ideal' conditions) and 'effectiveness' (performance under 'everyday' conditions) must be maintained. In addition to the unique contexts in which efficacy is assessed, the less ideal situations of everyday practice must in future be given separate consideration before place in management of an illness can be considered comprehensively adjudged. 


\section{And now for something completely different...}

It is surprising, considering the elusiveness of a unifying pharmacological property, the weakness of the primary validating parameter and the limitations inherent in clinical appraisal that enthusiasm for things 'new' was not balanced by circumspection as to whether they were genuinely a-typical. Some did urge caution in reading too much into 'atypical' (World Psychiatric Association, 2002), but attempts to neutralise its specific implications by alternatives such as 'new' or 'second generation' only reinforced the perception that what was 'new' must indeed be 'different', for it still demanded subclassification.

How could such a scantly dressed concept feel so cosy in the psychiatric vernacular? As its foundations weaken, one must point out that the idea has become entrenched in professional consciousness with a surety that, outside religious conviction, is nowadays usually instilled only by the subtle and pervasive workings of those for whom 'atypical' always played a strong hand - the marketing men! Maybe this was simply the term that industry adopted to delineate its post-clozapine products, creating in the minds of prescribers 'clear blue water' between what was 'new' and what was just 'conventional', an image powerfully boosted by association with the one thing that was un-typical, clozapine.

This proposition will be too radical for many but is worth debating. Indeed, in a revivified climate of questioning can we turn the spotlight on clozapine too?

\section{Clozapine - enhanced efficacy or enhanced tolerability?}

Even those who accept the wounding, if not death, of atypicality will accept that clozapine is different. The USMulticenter Study (Kane et al, 1988) suggested advantage in three domains:

- neurological: reduced liability to extrapyramidal side-effects (i.e. enhanced tolerability)

- negative symptomatology: specific efficacy

- positive symptomatology (in treatment resistance): enhanced efficacy.

\section{Effects on extrapyramidal function}

The ultimate test of a drug's liability to cause extrapyramidal side-effects would be in people with idiopathic extrapyramidal disease, although in contrast to the frequency of claims for atypicality, there has been striking reluctance to utilise this model.

Two randomised controlled trials clearly demonstrated the antipsychotic benefits of clozapine for psychosis in people with Parkinson's disease, without exacerbation of motor disorders (Friedman et al, 1999; Pollak et al, 1999). These effects are sustained (Factor et al, 2001) and may be associated with longterm improvements in mortality (Factor et al, 2003). This is a unique profile, for although similar benefits have been claimed for low-dose quetiapine, these come mainly from open or retrospective studies, double-blind prospective data being less encouraging (Rabey et al, 2007). There is no evidence that claims for other new drugs stand on this test.

Clozapine's advantage in terms of extrapyramidal tolerability seems unique within its class. But are extrapyramidal advantages restricted just to the neurological sphere or can they influence other areas -i.e. are they domain-specific?

\section{Effects on negative and positive symptomatology - efficacy or tolerability?}

Clozapine is associated with reduction in negative symptom scores (Kane et al, 1988). Interpretation is, however, muddied by the conceptual confusion that has surrounded schizophrenic negativity for the past quarter of a century.

This arose as an unanticipated consequence of Crow's type 1 /type 2 hypothesis, which postulates that authentic negative symptoms are based on structural brain changes, and should therefore show 'a component of irreversibility' with antipsychotics (Crow, 1980). This was strongly contested and became the most fruitful source of hypothesisgenerated research in psychiatry throughout the 1980s. However, testing forced a conceptual shift. Traditionally, schizophrenic negativity (or 'defect') was largely considered in higher, broad-based functional domains such as psychosocial and occupational competence, assessed longitudinally, often over years (Kant, 1943; Jilek, 1968). Although some researchers had considered chronic deficits cross-sectionally (e.g. the activity-withdrawal dichotomy (Venables, 1957; Depue, 1976)), it now became imperative to convert negativity into something symptom-driven, measurable crosssectionally. Whereas the reliability of this process was established for the many rating scales devised to address the question, the validity of the exercise never was and it remains unclear to what extent the varied clinical states that present 'negatively' (Carpenter et al, 1985) can be separated by crosssectional clinical assessment alone. 


\begin{tabular}{|c|c|c|}
\hline & Parkinsonism & Negative schizophrenia \\
\hline Facial expression & $\begin{array}{l}\text { 'Masked' } \\
\text { Loss of facial contours } \\
\text { Loss of gradations of expression } \\
\text { Eye contact preserved } \\
\text { Staring 'reptilian' gaze from reduced } \\
\text { blink rate } \\
\text { Parted lips }\end{array}$ & $\begin{array}{l}\text { Fixed through emotional range } \\
\text { 'Empty' /'vapid' } \\
\text { Avoidance of eye contact } \\
\text { Gradation maintained, variety lost }\end{array}$ \\
\hline Mood & $\begin{array}{l}\text { Dysphoria and depression may or may } \\
\text { not be present } \\
\text { Range and depth retained }\end{array}$ & Range and depth restricted \\
\hline Speech & $\begin{array}{l}\text { Loss of pitch, power and intonation } \\
\text { Impaired articulation } \\
\text { Spontaneous generation of words } \\
\text { generally preserved }\end{array}$ & $\begin{array}{l}\text { Loss of intonation } \\
\text { Articulation preserved } \\
\text { Reduced word usage }\end{array}$ \\
\hline Posture & $\begin{array}{l}\text { Characteristically mild hyperextension } \\
\text { May show nuchal/thoracic flexion } \\
\text { 'Actively imposed' disorder }\end{array}$ & $\begin{array}{l}\text { No characteristic change } \\
\text { May be avoidant ('aversive') and } \\
\text { awkward }\end{array}$ \\
\hline Engagement/rapport & Preserved & Impaired - the 'brick wall' \\
\hline
\end{tabular}

A major problem is the bradykinesia of druginduced parkinsonism, which in both its objective and subjective characteristics can be difficult, if not impossible, to distinguish from primary negative schizophrenic states (Owens, 1999) (Table 4). Any drug claiming efficacy in negative states cannot produce change simply by reducing bradykinesia (or other 'secondary' phenomena). In this light, even clozapine's benefits are not clear-cut. Breier et al (1994) found that improvements in negative states were restricted to those who did not satisfy criteria for 'deficit' schizophrenia (Carpenter et al, 1988), a concept that, by incorporating time/durability criteria, to some extent reconnects with the traditional idea of schizophrenic negativity.

Thus, are clozapine's benefits in negative states efficacy or tolerability? With its uniquely benign extrapyramidal side-effects profile, could improvements on switching not reflect the waning of prior extrapyramidal features, especially the subjective component of bradykinesia? Indeed, if negative states rateable on standardised rating scales for negative symptoms can emerge in normal volunteers administered antipsychotics liable to cause extrapyramidal side-effects (Ramaekers et al, 1999; Artaloytia et al, 2006) should this not be the initial assumption to be disproved rather than the more ambitious, if appealing, alternative so widely accepted? Applying statistical methods to the issue does not address the point that the problem is clinical, not analytical.

This interpretation could be extended to all recently released antipsychotics for which efficacy in negative states has been claimed but poorly substantiated
(Keefe et al, 1999) - new drugs, regardless of inherent extrapyramidal side-effect profiles, prescribed within much tighter (and equivalently lower) licensed dosages than earlier compounds, setting up better tolerability to create a mirage of efficacy. It might also explain contradictions in the large and complex literature that set out to test Crow's hypothesis, summary of which now forces doubt that anything currently available can deliver efficacy to these stubborn states (Erhart et al, 2006).

Recently, a consensus group of the US National Institute of Mental Health reiterated that in developing treatments for negative states the distinction between primary and secondary is 'not essential' (Kirkpatrick et al, 2006). This implies that the way in which clinical improvements are conceptualised might not be of crucial importance and, contrary to the suggestion here, that clinical confusion does not lie buried deep in a quarter of a century's lack of progress in the therapeutics of negative states.

Would it matter, though, if conceptual confusion were contributing to another fundamental misunderstanding? A further intriguing question is whether clozapine's extrapyramidal tolerability can also explain enhanced efficacy in the positive symptom domain.

There is a long but curiously disregarded literature pointing to escalating antipsychotic doses triggering the law of diminishing returns - sometimes referred to as neuroleptic or behavioural toxicity (Wilkens and Malitz, 1960; Simpson et al,1976). Recent studies support this, even with clozapine (Pollack et al, 1995). Reviewing dose-response relationships and blood 
levels, Baldessarini et al (1990) suggested that the curvilinear relationships most frequently reported may reflect the development of 'untoward neurological side-effects'. Further, in the immediate preclozapine years it was proposed that strategies designed specifically to diminish extrapyramidal side-effects might be associated with clinical improvement in refractory schizophrenia (Opler et al, 1985).

As with benefits in the negative domain, is it not possible - probable even - that improvements in positive symptoms following the switch to clozapine result from removal of the extrapyramidally mediated dysphoria that, when present, drives such symptoms, and hence that they reflect tolerability rather than efficacy? Again, in view of what the literature holds, one wonders why this was not the initial, rather than the by now somewhat radical, supposition.

The view that benefits are benefits however mediated and distinctions between efficacy and tolerability are hardly important is seductive and clinicians in particular might chorus 'So what?' in response to the above. Perhaps one of the most important lessons our journey back might teach us, one of the darkest shadows that has haunted our path this past decade, is that we, as clinicians, have a profoundly shallow grasp of the clinical pharmacology of antipsychotics, ignorance that sits comfortably on a bed of 'so what?' If this view seems arrogant, ask oneself why we - an entire profession - must now face a dramatic turn-around in our perception of one of our most important therapeutic agents. Conceptualisation bears fundamentally on interpretation of trial data and hence on advice clinicians offer to patients as well as to preclinical colleagues on whose expertise future developments depend. If, at our current crossroads, there are only 'soft' lessons to be learned, 'selective' implications to salvage, we stand embarrassed indeed.

\section{Back to basics?}

None of the recent data challenges the claim of new antipsychotics to a prominent place in the therapeutic armamentarium. However, neither do they support the universal downgrading of compounds that came before. Although clozapine is indeed 'novel' (perhaps emblematic of future aspirations), in evidence terms we still have a single class of antipsychotics, each member of which comes with its own balance of advantages and disadvantages. And each can find a place in individual patient care. RIP atypical!

Such simple reappraisal could be self-affirming for doctors increasingly constrained within a suffocating blanket of protocols, guidelines, treatment algorithms, etc., each telling them how treatment ought to be ordered. While the application of evidence-based principles achieves the admirable goal of driving down idiosyncratic care, the claim by which it is most frequently promoted - driving up quality care-appears less sound the more it is scrutinised. Overadherence to guidelines fosters algorithmic, tickbox practice that limits choice, deskills professionals and risks enshrining out-of-date information. Worst of all, it restricts clinicians' responses to those individual, uniquely personal aspects of each patient and each illness. The active imposition of homogeneity on trial populations reflects discordantly against the heterogeneous presentations of everyday practice and some bridging of the two is necessary.

How might current findings be translated into practice? One example comes from drug regulation. Granting a marketing authorisation is not based on detached consideration of efficacy $v$. safety separately but on their integration into a risk/benefit assessment, a concept in which clinical judgement (i.e. the interposition of context) comprises the added extra. Recent data encourage a repositioning of patient 'context' at the heart of treatment planning via individualised risk/benefit appraisal. One example is outlined in Fig. 2 , although there are many others. CATIE and the rest have provided a broader set of considerations to enter into this clinical decision-making exercise.

Furthermore, viewing antipsychotics as a single class widens enormously the available options, for it is a class that can be looked at from many angles (potency, $\mathrm{D}_{2}$ selectivity, additional cholinergic, histaminic and adrenergic actions, metabolic profile, etc.), the only one less useful than typical/atypical being the chemical groupings by which textbooks still present them.

Individualised risk/benefit appraisal does not negate the value of guidelines but does allow challenge to their increasingly dogmatic assertions and proscriptive options, restricting them, as their name implies, to general frameworks comprising large headings above small detail. Rather than simply highlighting professional weaknesses, recent data can open the way to more sophisticated psychopharmacological practice characterised by individualised care, an essential element of genuine quality that not only offers better prospects for patients but will reinvigorate a key element of psychiatric professionalism-expertise in prescribing - that with the ascent of 'guidelines' has tended to wither.

As Dorothy discovered, there is more of worth to be found in your own backyard than in some mythical Land of Oz over the rainbow.

\section{Declaration of interest}

D.O. is a former member of the Committee on Safety of Medicines and a current member of the Expert 


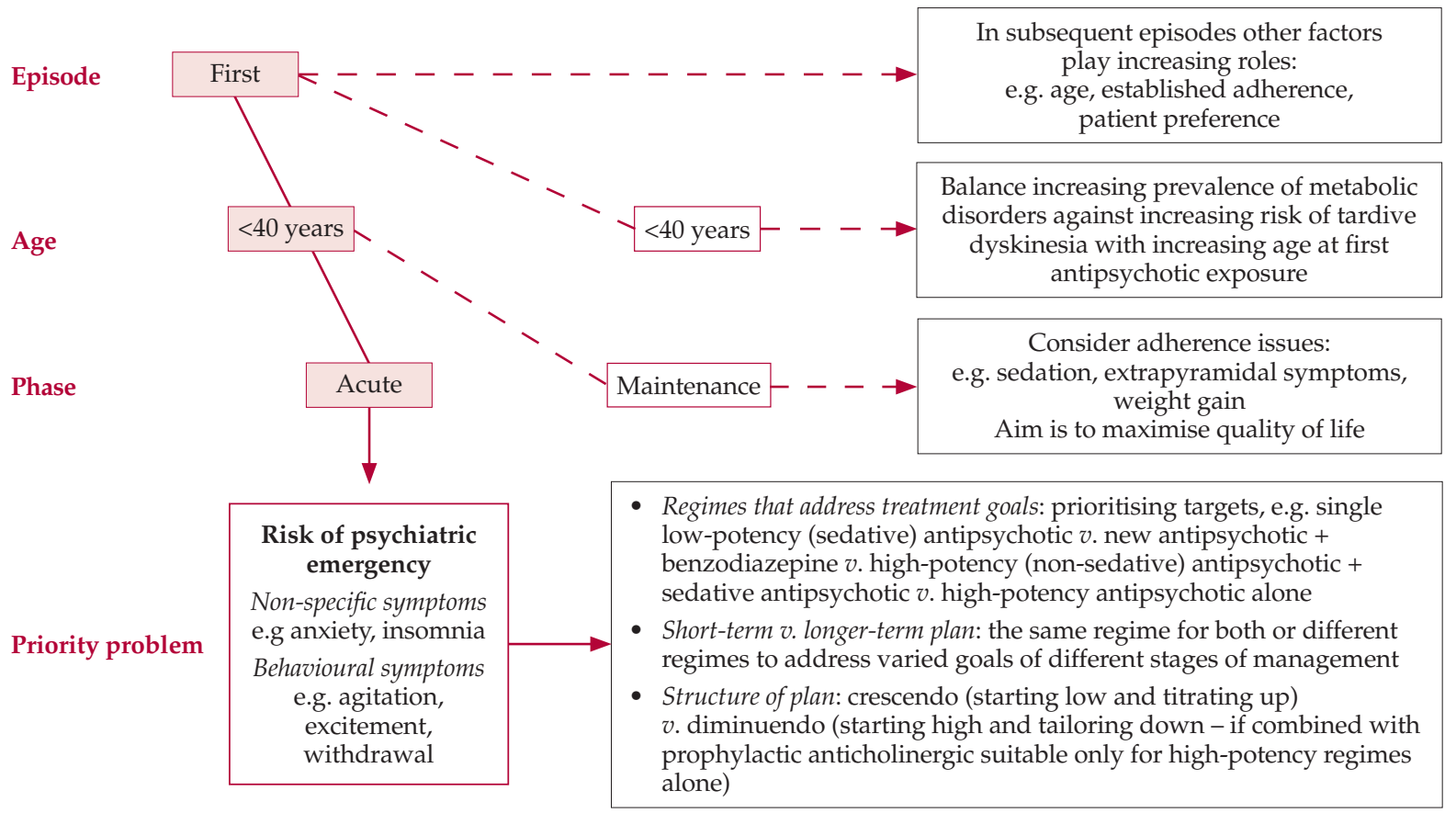

Adherence assessment

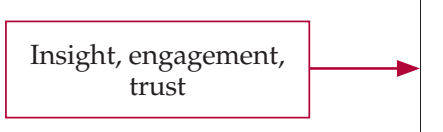

- Emphasis on enhancing tolerability (i.e. avoiding sedation, extrapyramidal symptoms) in patients with tenuous engagement/trust

- Consider rate of increments (ultra slow in those poorly engaged)

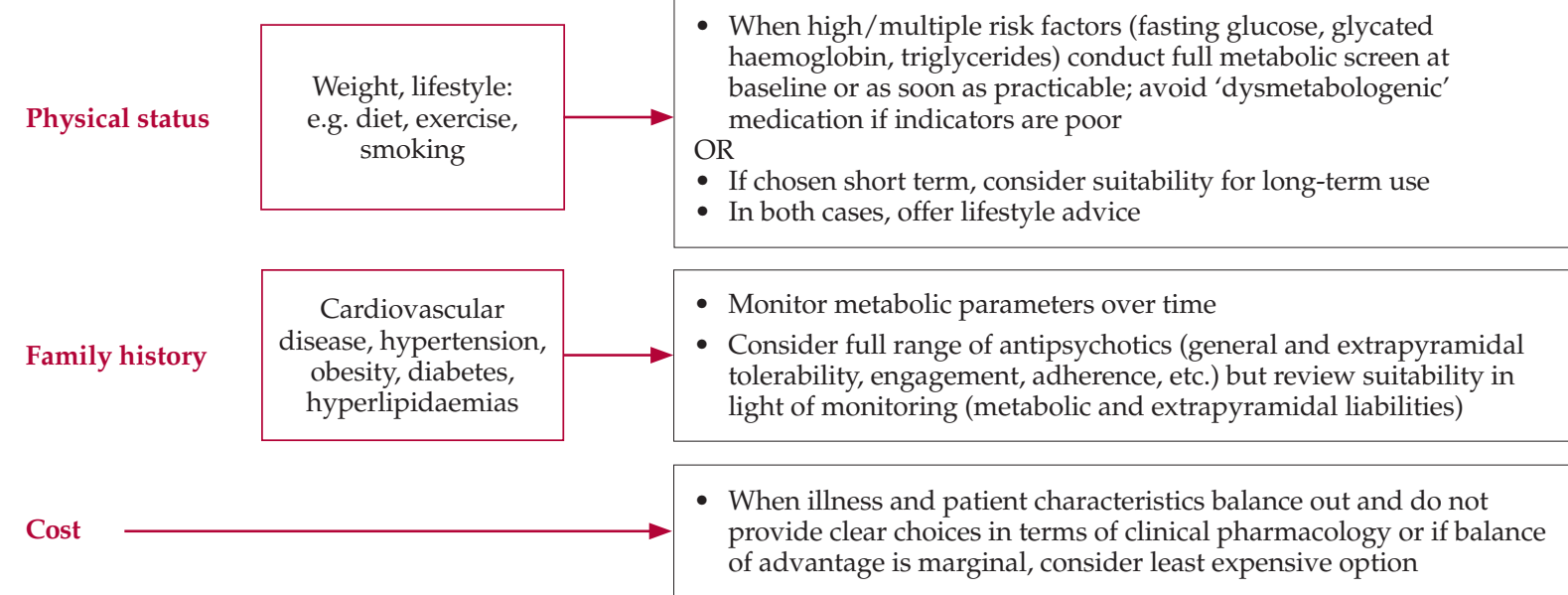

Fig. 2 Some issues in individual risk/benefit appraisal with antipsychotic prescribing (illustrated in relation to first and acute presentations).

Advisory Panel on Psychiatry and Old AgePsychiatry of the UK Commission on Human Medicines. He has no associations with industry.

\section{References*}

Artaloytia, F., Arango, C., Lahti, A., et al (2006) Negative signs and symptoms secondary to antipsychotics: a double-blind, randomised trial of a single dose of placebo, haloperidol, and risperidone in healthy volunteers. American Journal of Psychiatry, 163, 488-493.

Baldessarini, R. J., Katz, B. \& Cotton, P. (1984) Dissimilar dosing with high-potency and low-potency neuroleptics. American Journal of Psychiatry, 141, 748-752.
Baldessarini, R. J., Cohen, B. M \& Teicher, M. H. (1988) Significance of neuroleptic dose and plasma level in the pharmacological treatment of psychosis. Archives of General Psychiatry, 45, 79-91.

Baldessarini, R. J., Cohen, B. M. \& Teicher, M. H. (1990) Pharmacological treatment. In Schizophrenia: Treatment of Acute Psychotic Episodes (eds S. Levy \& P. Ninan), pp. 61-118. American Psychiatric Press.

Breier, A., Buchanan, R. W., Kirkpatrick, B., et al (1994) Effects of clozapine on positive and negative symptoms in outpatients with schizophrenia. American Journal of Psychiatry, 151, 20-26.

Carpenter, W. T., Heinrichs, D. W. \& Alphs, L. D. (1985) Treatment of negative symptoms. Schizophrenia Bulletin, 11, $440-452$. 
Carpenter, W. T., Heinrichs, D. W. \& Wagman, A. M. (1988) Deficit and non-deficit forms of schizophrenia: the concept. American Journal of Psychiatry, 145, 578-583.

Cassano, G. C., Castrogiovanni, P. \& Conti, L. (1975) Sulpiride versus haloperidol in schizophrenia: a double-blind comparative study. Current Therapeutic Research, 17, 189-201.

Chakos, M., Lieberman, J. A., Hoffman, E., et al (2001) Effectiveness of second-generation antipsychotics in patients with treatment-resistant schizophrenia: a review and metaanalysis of randomised trials. American Journal of Psychiatry, 158, 518-526.

Chiles, J. A. (1978) Extrapyramidal reactions in adolescents treated with high potency antipsychotics. American Journal of Psychiatry, 135, 239-240.

Costall, B. \& Naylor, R. J. (1975) Detection of the neuroleptic properties of clozapine, sulpiride and thioridazine. Psychopharmacologia, 43, 69-74.

Crow, T. J. (1980) Molecular pathology of schizophrenia: more than one disease process? BMJ, 280, 66-68.

Crow, T. J. (1987) The dopamine hypothesis survives, but there must be a way ahead. British Journal of Psychiatry, 151, 460-465.

Davis, J. M., Chen, N. \& Glick, I. D. (2003) A meta-analysis of the efficacy of second-generation antipsychotics. Archives of General Psychiatry, 60, 553-564.

Depue, R. A. (1976) An activity-withdrawal distinction in schizophrenia: behavioural, clinical, brain damage and neuropsychological correlates. Journal of Abnormal Psychology, 85, 174-185.

Elizur, A. \& Davidson, S. (1975) The evaluation of the anti-autistic activity of sulpiride. Current Therapeutic Research, 18, 578-584.

Erhart, S. M., Marder, S. R. \& Carpenter, W. T. (2006) Treatment of schizophrenia negative symptoms: future prospects. Schizophrenia Bulletin, 32, 234-237.

Factor, S. A., Friedman, J. H., Lannon, M. C., et al (2001) Clozapine for the treatment of drug-induced psychosis in Parkinson's disease: results of the 12 week open label extension in the PSYCLOPS trial. Movement Disorders, 16, 135-139.

Factor, S. A., Feustel, P. J., Freidman, J. H., et al (2003) Longitudinal outcome of Parkinson's disease patients with psychosis. Neurology, 60, 1756-1761.

Friedman, J., Lannon, M., Cornelia, C., et al (1999) Low-dose clozapine for the treatment of drug-induced psychosis in Parkinson's disease. New England Journal of Medicine, 340, 757-763

Geddes, J., Freemantle, N., Harrison, P., et al (2000) Atypical antipsychotics in the treatment of schizophrenia: systematic overview and meta-regression analysis. BMJ, 321, 1371-1376.

Heres, S., Davis, J., Maino, K., et al (2006) Why olanzapine beats risperidone, risperidone beats quetiapine, and quetiapine beats olanzapine: an exploratory analysis of head-to-head comparison studies of second-generation antipsychotics. American Journal of Psychiatry, 163, 185-194.

Janno, S., Holi, M. M., et al (2005) Validity of Simpson-Angus Scale (SAS) in a naturalistic schizophrenia population. BMC Neurology, 5. doi: 10.1186/1471-2377-5-5.

Jenner, P. \& Marsden, C .D. (1979) The substituted benzamides - a novel class of dopamine antagonists. Life Sciences, 25, $479-486$

Jenner, P., Hall, M. D., Murugaiah, K., et al (1982) Repeated administration of sulpiride for three weeks produces behavioural and biochemical evidence for cerebral dopamine receptor supersensitivity. Biochemical Pharmacology, 31, 325-328.

Jilek, W. G. (1968) The residual dimension: a study of residual syndromes in veterans with chronic psychiatric illness. Psychiatria Clinica, 1, 175-191.

Jones, P. B., Barnes, T., Davies, L., et al (2006) Randomised controlled trial of the effect on quality of life of second- vs first-generation antipsychotic drugs in schizophrenia. Archives of General Psychiatry, 63, 1079-1087.

Kane, J., Honigfeld, G., Singer, J., et al (1988) Clozapine for the treatment-resistant schizophrenia: a double-blind comparison with chlorpromazine. Archives of General Psychiatry, 45 789-796.

Kant, O. (1943) Clinical analysis of schizophrenic deterioration. Psychiatric Quarterly, 17, 426-445.
Kapur, S., Zipursky, R., Roy, P., et al (1997) The relationship between $\mathrm{D}_{2}$ receptor occupancy and plasma levels on low dose oral haloperidol: a PET study. Psychopharmacology, 131, 148-152.

Keefe, R. S., Harvey, P. D., Lenzenweger, M. F. et al (1999) Efficacy and extrapyramidal side-effects of the new antipsychotics olanzapine, quetiapine, risperidone and sertindole compared to conventional antipsychotics and placebo: a meta-analysis of randomised controlled trials. Schizophrenia Research, 35, 51-68.

Kinon, B.J. \& Lieberman, J.A. (1996) Mechanisms of action of atypical antipsychotic drugs: a critical analysis. Psychopharmacology, 124, 2-34.

Kirkpatrick, B., Fenton, W. S., Carpenter, W. T., et al (2006) The NIMH-MATRICS consensus statement on negative symptoms. Schizophrenia Bulletin, 32, 214-224.

Leucht, S., Engel, R. R., Bauml, J., et al (2007) Is the superior efficacy of new generation antipsychotics an artifact of LOCF? Schizophrenia Bulletin, 33, 183-191.

Lieberman, J. A., Phillips, M., Gu, H., et al (2003) Atypical and conventional antipsychotic drugs in treatment-naïve firstepisode schizophrenia: a 52-week randomised trial of clozapine vs chlorpromazine. Neuropsychopharmacology, 28, 995-1003.

Lieberman, J. A., Stroup, T. S., McEvoy, J. P., et al (2005) Effectiveness of antipsychotic drugs in patients with chronic schizophrenia. New England Journal of Medicine, 353, 1209-1223.

Marsden, C. D., Mindham, R. H. \& Mackay, A. V. (1986) Extrapyramidal movement disorder produced by antipsychotic drugs. In The Psychopharmacology and Drug Treatment of Schizophrenia (eds P. Bradley \& S. Hirsch), pp. 340-402. Oxford University Press.

McEvoy, J. P., Hogarty, G. E. \& Steingard, S. (1991) Optimal dose of neuroleptic in acute schizophrenia. Archives of General Psychiatry, 48, 739-745.

Miller, R. J. \& Hiley, C. R. (1974) Anti-muscarinic properties of neuroleptics and drug-induced parkinsonism. Nature, 248, 596-597.

Oosthuizen, P., Emsley, R. A., Turner, J., et al (2001) Determining the optimal dose of haloperidol in first-episode psychosis. Journal of Psychopharmacology, 15, 251-255.

Opler, L. A., Kay, S. R. \& Vital-Herne, J. (1985) Combined mesoridazine and amantadine treatment in refractory schizophrenics. Current Therapeutic Research, 37, 318-325.

Owens, D. C. (1998) The drug treatment of schizophrenia. In Seminars in General Adult Psychiatry: Volume 1 (eds G. Stein \& G. Wilkinson), pp 381-449. Gaskell.

Owens, D. G. C. (1999) A Guide to the Extrapyramidal Side-Effects of Antipsychotic Drugs. Cambridge University Press.

Pollack, S., Lieberman, J. A., Fleischhacker, W. W., et al (1995) A comparison of European and American dosing regimens of schizophrenic patients on clozapine: efficacy and side-effects. Psychopharmacology Bulletin, 31, 315-320.

Pollak, P., Destee, A., Tison, F., et al (1999) Clozapine in drug-induced psychosis in Parkinson's disease. Lancet, 353, 2041-2042.

Polsky, D., Doshi, J. A., Bauer, M. S, et al (2006) Clinical trial-based cost-effectiveness analysis of antipsychotic use. American Journal of Psychiatry, 163, 2047-2056.

Rabey, J. M., Prokhorov, T., Moniovitz, A., et al (2007) Effect of quetiapine in psychotic Parkinson's disease patients: a doubleblind labelled study of 3 months duration. Movement Disorders, 22, 313-318.

Ramaekers, J. G., Louwerens, J. W., Muntjewerff, N. D., et al (1999) Psychomotor, cognitive, extrapyramidal, and affective functions of healthy volunteers during treatment with an atypical (amisulpride) and a classic (haloperidol) antipsychotic. Journal of Clinical Psychopharmacolooy, 19, 209-221.

Reynolds, G. P. (2004) Receptor mechanisms in the treatment of schizophrenia. Journal of Psychopharmacology, 18, 340-345.

Rosebush, P. I. \& Mazurek, M. F. (1999) Neurologic side effects in neuroleptic-naïve patients treated with haloperidol or risperidone. Neurology, 52, 782-785.

Rosenheck, R. (2005) Effectiveness versus efficacy of secondgeneration antipsychotics: haloperidol without antipsychotics as a comparator. Psychiatric Services, 56, 85-92.

Rosenheck, R., Perlick, D., Bingham, S., et al (2003) Effectiveness and cost of olanzapine and haloperidol in the treatment of schizophrenia: a randomised controlled trial. JAMA, 290, 2693-2702. 
Rosenheck, R., Leslie, D., Sindelar, J., et al (2006) Cost-effectiveness of second-generation antipsychotics and perphenazine in a randomised trial of treatment for chronic schizophrenia. American Journal of Psychiatry, 163, 2080-2089.

Rosenheck, R., Swartz, M., McEvoy, J., et al (2007) Second-generation antipsychotics: reviewing the cost-effectiveness component of the CATIE trial. Expert Review of Pharmacoeconomics and Outcomes Research, 7, 103-111.

Simpson, G. M., \& Angus, J. W. S. (1970) A rating scale for extrapyramidal side-effects. Acta Psychiatrica Scandinavica Supplementum, 212, 11-19.

Simpson, G. M., Varega, E. \& Haber, E. J. (1976) Psychotic exacerbations produced by neuroleptics. Diseases of the Nervous System, 37, 367-369.

Toru, M., Shimazonio, Y., Miyasaka M., et al (1972) A doubleblind comparison of sulpiride with chlorpromazine in chronic schizophrenia. Journal of Clinical Pharmacology, 12, 221-229.

Ungvari, G. S., Chiu, H., Lam, L., et al (1999) Gradual withdrawal of long-term anticholinergic antiparkinson medication in Chinese patients with chronic schizophrenia. Journal of Clinical Psychopharmacology, 19, 141-148.

Venables, P. H. (1957) A short scale for rating 'activity-withdrawal' in schizophrenics. Journal of Mental Science, 103, 197-199.

Weiden, P.J., Mann, J. J., Hass, G., et al (1987) Clinical non-recognition of neuroleptic-induced movement disorders: a cautionary study. American Journal of Psychiatry, 144, 1148-1153.

Wilkens, B. \& Malitz, S. (1960) Some problems of dose variations in the use of tranquillising drugs. American Journal of Psychiatry, 117, 23-29.

World Psychiatric Association (2002) The usefulness and use of second-generation antipsychotic medications (eds D. Kupfer \& N. Sartorius). Current Opinion in Psychiatry, 15 (suppl. 1), S1-S51.

* A more comprehensive list of references is available from the author.

\section{MCQs and EMI}

1 The concept of atypicality is founded on:

a limbic as opposed to nigrostriatal selectivity of action

$\mathrm{b}$ a reduced liability to promote hyperprolactinaemia

c 'loose' receptor-binding properties

d efficacy on negative symptoms

e diminished liability to promote parkinsonism.

2 According to the CATIE study:

a olanzapine was clearly the most effective antipsychotic

b risperidone was associated with the lowest rate of discontinuation for intolerable side-effects

c perphenazine use was associated with an increased incidence of extrapyramidal side-effects

d cost-effectiveness benefits were evident for ziprasidone

e over 18 months, quetiapine was an ineffective antipsychotic.

3 In relation to antipsychotic drugs:

a linear dose-response relationships are the norm

b Crow's type 1 /type 2 hypothesis has been disproven

c high lipophilicity and brain penetrance is characteristic of all class members

d liability to extrapyramidal side-effects is independent of rate of dose increment

e high-potency compounds are utilised in equivalently higher doses than low-potency compounds.

4 With regard to clozapine:

a it was considered 'atypical' only after publication of the US Multicenter Study in 1988

b its extrapyramidal tolerability profile is, on current evidence, unique c benefits in dopaminomimetic psychoses are offset by increased mortality

d its benefits in treatment-resistant schizophrenia are clinically substantial

e its benefits in negative states extend to those with durable disorder.

\section{EMI}

The following EMI, which requires reading outside of this article, offers readers a more taxing self-assessment.

\section{Theme: 'Risk-benefit appraisal' in therapeutics}

Options

a slow-release trifluoperazine $20 \mathrm{mg}$ at night

b olanzapine (as orodispersible tablets) $10 \mathrm{mg}$ at night

c chlorpromazine $100 \mathrm{mg}$ three times a day $+200 \mathrm{mg}$ at night

d haloperidol $10 \mathrm{mg}$ three times a day

e risperidone $2 \mathrm{mg}$ at night

$\mathrm{f}$ quetiapine $50 \mathrm{mg}$ twice a day $+150 \mathrm{mg}$ at night

$\mathrm{g}$ perphenazine $4 \mathrm{mg}$ in the morning $+8 \mathrm{mg}$ at night + regular benzodiazepine

$\mathrm{h}$ amisulpride $200 \mathrm{mg}$ twice a day + chlorpromazine as required up to $400 \mathrm{mg}$ per day

i sulpiride $200 \mathrm{mg}$ in the morning $+400 \mathrm{mg}$ at night

j zuclopentixol decanoate, $200 \mathrm{mg}$ immediately, aiming for a two-weekly regime

$\mathrm{k}$ aripiprazole $15 \mathrm{mg}$ at night

1 clozapine, aiming for $100 \mathrm{mg}$ twice a day $+200 \mathrm{mg}$ at night.

Choose TWO of the treatment schedules above as representing the most reasonable initial options for each of the following clinical scenarios:

i A 46-year-old man (BMI 34) who smokes 30 cigarettes a day and admits to drinking 40 units of alcohol a week, presenting with first-episode, late-onset psychosis into which he has no insight.

ii A 19-year-old man, suspicious, restless and sleeping poorly, who committed an unprovoked attack on a stranger before admission and admits to imperative hallucinations ordering him to kill his persecutors.

iii An obese 56-year-old woman with epilepsy well maintained on low dose of depot for many years, presenting with social decline characterised by apathy, withdrawal and deteriorating personal hygiene. On examination, her clothes are food-stained and cigarette burned. Articulation is impaired, she has a postural tremor and marked akathisia.

\section{MCQ answers}

$\begin{array}{llllll}1 & & 2 & & 3 & 4 \\ \text { a F } & \text { a F } & \text { a F } & \text { a F } \\ \text { b F } & \text { b T } & \text { b F } & \text { b T } \\ \text { c F } & \text { c F } & \text { c F } & \text { c F } \\ \text { d F } & \text { d F } & \text { d F } & \text { d F } \\ \text { e } & \text { T } & \text { e F } & \text { e T } & \text { e F }\end{array}$

\section{EMI correct matchings}

$\begin{array}{lll}\text { i } & \text { ii } & \text { iii } \\ \text { e, g } & \text { c, h } & \text { f, i }\end{array}$

